\title{
Catheter-related Complications with Totally Implantable Venous Access Devices in Patients with Gynecologic Malignancies
}

Kristina Ernst ( $\nabla$ kristina.ernst@uniklinik-ulm.de )

University Hospital Ulm

Carolin Bärtels

University Hospital Ulm

Nikolaus de Gregorio

University Hospital Ulm

\section{Florian Ebner}

Helios Amper-Klinikum Dachau

Fabienne Schochter

University Hospital Ulm

Davut Dayan

University Hospital Ulm

Wolfgang Janni

University Hospital Ulm

Thomas Friedl

University Hospital Ulm

Amelie de Gregorio

University Hospital Ulm

\section{Research Article}

Keywords: Catheter-associated complications, thrombosis, infection, gynecologic malignancies, totally implanted venous access devices (TIVAD)

Posted Date: February 5th, 2021

DOI: https://doi.org/10.21203/rs.3.rs-150258/v1

License: (1) (1) This work is licensed under a Creative Commons Attribution 4.0 International License.

Read Full License 


\section{Abstract}

Background: The implantation of a subcutaneous implantable venous access device in patients with a gynecological cancer disease could be necessary because of different causes, e.g. application of chemotherapy or parenteral nutrition in case of advanced cancer. 4 years after implementation of the Seldinger-technique in the subclavian vein as standard way of port-catheter-implantation at department of gynecology at the University-Hospital in Ulm a retrospective analysis of complication-rates was performed to define internal standards for this procedure.

Methods: Between 01/2014 and 07/2018 we reviewed all patients who received a port implantation at the gynecological department. The standard way of port-implantation used in this cohort was Seldingertechnique. All Data assessed were used anonymously. Patients-characteristics, tumor-entity, surgical and anesthesiological management, morbidity and port catheter associated complications (thrombosis, infections etc.) were analyzed.

Results: A total of 638 were included. The implantation was performed in Seldinger-technique. Port catheter implantation was successfully performed in $96.6 \%$. The implantation on the left subclavian vein significantly showed a higher rate of success than in the right subclavian vein $(98.2 \%$ vs. $95.3 \%, p=0,036)$. Significant higher rates of associated thromboses was found in patients with a port implantation on the left side ( $5.9 \%$ vs. $2.0 \% ; p=0.036)$. Obesity $\left(B M I \geq 30 \mathrm{~kg} / \mathrm{m}^{2}\right)$ leads to a significant higher rate of venous misplacements $(p=0.027)$. Compared to local anesthesia and analgosedation, general anesthesia leads to a significant lower rate of perioperative complications ( $20.3 \%$ vs. $22.4 \%$ vs. $13.1 \%$; $p=0.014)$.

Perioperative application of antibiotics seems to reduce postoperative infection rates, even if the results are not significant.

Conclusion: Seldinger-Technique is an efficient way for port-implantation. Especially patients with a high potential of complications, like obesity with $\mathrm{BMI}>30 \mathrm{~kg} / \mathrm{m}^{2}$, or other risk factors, the left subclavian vein should be preferred, as well as general anesthesia. Perioperative application of antibiotics (e.g. singleshot antibiotics) should be considered.

Trial registration: retrospectively registered

\section{Introduction}

In 1982 Niederhuber et al. reported the first successfully implanted TIVADS (totally implantable venous access device) in patients with oncological disease for application of chemotherapy [1]. Nowadays, implantable venous access devises are widely used in oncological treatments for different indications. Next to application of chemotherapy or anti-neoplastic agents, they also function for (long-term) parenteral nutrition. Whereas some patients need TIVADs due to insufficient peripheral venous situation, also some vasotoxic chemotherapy agents require administration via central venous access devises $[2,3$, 4]. Due to their total subcutaneous position, TIVADs are the preferred venous access systems in oncology 
and allow comfortable and safe handling. Compared to temporary central venous devices, TIVADs require less effort for daily care and are associated with lower infection rates and less limitations in daily life [5].

Currently, there are two surgical techniques used by surgeons, gynecologists and sometimes radiologists to access the central venous system. Next to the classical "venous cutdown-technique" (CT) also the „surface landmark" method in Seldinger-Technique (ST) allows TIVAD implantation. For cutdowntechnique, usually preparation of the cephalical vein in the clavipectoral triangle is performed to access the subclavian vein. In contrast to the $\mathrm{CT}$ technique, Seldinger technique uses blind puncture of the subclavian vein in which the clavicle serves as landmark. After the successful puncture of the vein, a guide-wire is inserted through the needle and allows implantation of the catheter into the subclavian vein.

Complications associated with TIVAD implantation could be caused by the surgical procedure itself or during postoperative course by the implanted material and its use (e.g. thrombosis or infection). In addition to categorization by type, complications can also be categorized according to timing of the incidence. Early complications which are mostly related to surgery differ from late complications usually associated with long-term use (e.g. infection after surgery vs infection during the course of long-term use for parenteral nutrition). In general, morbidity due to implanted TIVADs mostly consists of vascular injury, malposition, thrombosis, impaired wound healing, malfunction, or infection. Some complications may also be influenced by the used technique, and specifically the complication "pneumothorax" may be associated with ST. Some of the complications may also be related to patient- or tumor characteristics such as obesity, tumor load or history of thrombosis.

For more appropriate counseling of patients undergoing TIVAD implantation and potential identification of patients with higher risk for suffering from implantation related morbidity or increased likelihood of unsuccessful implantation, a retrospective data analysis regarding patient characteristics, surgical details and outcome was performed.

\section{Materials And Methods}

\section{Study design:}

This retrospective study included anonymized data from all patients with gynecologic malignancies undergoing TIVAD implantation at the Department of Gynecology and Obstetrics, University Hospital Ulm, between January 2014 and June 2018. In January 2014, implantation of TIVADs was initiated and use of Seldinger-technique was chosen as standard method at our institution. Within the next 4.5 years, 638 patients underwent surgery for TIVAD implantation using this technique at our clinical center.

Data regarding the patient characteristics age, weight, body height, type of gynecological cancer, clinical setting and timing of chemotherapy were documented. To comprehensively assess surgical details and outcome, data on success of catheter implantation, time of catheter explantation (days after implantation), intraoperative single-shot antibiotics, anesthesiological procedures, previous history of thrombosis and therapeutic anticoagulation treatment were collected. In addition to the occurrence of 
complications (yes/no), time of occurrence (intra-/postoperative/both) and type of complication was recorded. Type of complications include venous malpositions, arterial puncture, infection, pneumothorax, thrombosis, impaired wound healing and other complications requiring revision. Time of occurrence of complications was categorized as intraoperative or postoperative only and assessment of postoperative complications was not limited with regard to time after surgery, as we wanted to include especially longterm complications such as thrombosis, malfunction or late infections. Date of TIVAD explantation was only recorded and analyzed in patients with explantation due to complications at our institution, as no follow-up data were available for patients that received routine TIVAD explantations in other hospitals (mainly healthy women without further contact to our institution).

All data were extracted from the available archived patient's documents and subsequently anonymized. All procedures performed in this study involving human participants were in accordance with the ethical standards of the institutional committee and ethical approval of the ethics committee of the University Ulm was given (320/18).

\section{TIVAD implantation}

Usually the puncture of the vein was performed blind and ultrasound as a technical additive was used only in individual cases. Anesthesia consists of local anesthesia, sedation with anesthesiological standby or general anesthesia. With preference for local anesthesia due to logistical reasons, anesthesia was chosen depending on patient's preference, extent of the operation (e.g. combination of port-catheterimplantation with breast-surgery etc.) or individual risk factors. In case of combination of surgical procedures, general anesthesia was obligatory. In patients with breast cancer and no further contraindications, the preferred side of port implantation is contralateral of the affected side. In all other cases, the left subclavian vein was favored because of the anatomical course of the vein. Four hours after the surgical procedure, $x$-ray of the chest was performed routinely for control of position of the TIVAD and especially to rule out a pneumothorax. Single-shot antibiotics during surgery was not mandatory and at surgeons' discretion or in cases of simultaneous surgery depending of the standard for antibiotics with the primary surgical procedure.

\section{Statistical methods:}

Descriptive statistics were presented in terms of absolute and relative frequencies for categorical data and in terms of medians and ranges for non-normally distributed metric data. To assess associations between categorical variables, the Chi-Square-Test was used; in cases of $2 \times 2$ contingency tables with expected cell frequencies of less than five, we used the exact Fisher test instead.

Statistical analysis was performed using SSPS 25.0 statistic software (IBM Corp, Armonk, New York, USA). The significance level was set to $p<0.05$ throughout, and there was no adjustment of a for multiple testing in this retrospective explorative analysis.

\section{Results}


Between January 2014 and June 2018, a total of 638 patients had a TIVAD implantation at the gynecological department of the University Hospital Ulm. All patients were female. The median age was 55 , median weight was $70 \mathrm{~kg} .71 \%$ of all patients had a normal or pre-adipose Body-Mass-Index (BMI). Most of the patients had breast-cancer as underlying cancer entity and the majority of patients underwent curative neoplastic treatment ( $81.2 \%)$. Only around $10 \%$ of the included patients had prior history of thrombosis or current anticoagulation. Patient characteristics are summarized in Table 1. 
Table 1

Patient characteristics $(\mathrm{N}=638)$

Age

Median in years (range)

$<40$

40-49

50-59

60-69

$\geq 70$

\section{Height}

Median in cm (range)

Weight

Median in $\mathrm{kg}$ (range)

BMI $\left(\mathrm{kg} / \mathrm{m}^{2}\right)$

$\mathrm{BMI}<18.5$

BMI 18.5-24.9

BMI 25.0-29.9

BMI 30.0-34.9

BMI 35.0-39.9

$\mathrm{BMI} \geq 40.0$

No information

Tumor entity
Total

Percentage

12.2

21.2

26.5

24.8

15.4

98

165 (143-189)

$70(35-135)$

16

2.5

263

41.2

192

30.1

89

13.9

44

6.9

16

2.5

18

2.8 


\begin{tabular}{|c|c|c|}
\hline & Total & Percentage \\
\hline $\mathrm{BC} \mathrm{MO}$ & 444 & 69.6 \\
\hline BC M1 & 62 & 9.7 \\
\hline OC MO & 54 & 8.5 \\
\hline OC M1 & 33 & 5.2 \\
\hline CC MO & 11 & 1.7 \\
\hline CC M1 & 4 & 0.6 \\
\hline EC MO & 4 & 0.6 \\
\hline EC M1 & 10 & 1.6 \\
\hline Others MO & 5 & 0.8 \\
\hline Others M1 & 10 & 1.6 \\
\hline No information* & 1 & 0.2 \\
\hline \multicolumn{3}{|c|}{ Therapeutic Situation } \\
\hline Neoadjuvant & 270 & 42.3 \\
\hline Adjuvant & 248 & 38.9 \\
\hline Palliative & 119 & 18.7 \\
\hline No information & 1 & 0.2 \\
\hline \multicolumn{3}{|c|}{ History of thrombosis } \\
\hline Yes & 41 & 6.4 \\
\hline No & 574 & 90.0 \\
\hline No information & 23 & 3.6 \\
\hline \multicolumn{3}{|l|}{ Anticoagulation } \\
\hline Yes & 46 & 7.2 \\
\hline No & 567 & 88.9 \\
\hline No information & 25 & 3.9 \\
\hline \multicolumn{3}{|c|}{$\begin{array}{l}\text { M0 = absence of metastases, } \mathrm{M} 1=\text { metastatic disease, } \mathrm{BC}=\text { breast cancer, } \mathrm{OC}=\text { ovarian cancer, } \mathrm{CC}= \\
\text { cervical cancer, } \mathrm{EC}=\text { endometrial cancer, Others = other rare gynecological tumor entity } \\
\text { (dysgerminoma, uterine sarcoma, müllerian mixed tumor, vulvar cancer, chorion carcinoma); * one } \\
\text { patient had ovarian cancer but information on M-status was missing }\end{array}$} \\
\hline
\end{tabular}

Table 2 shows the catheter-specific data. Overall, TIVAD implantation was successful in $96.9 \%$. A higher number of patients had TIVAD implantation on the left (53.0\%) than on the right side (47.0\%). More than 
half of the study-cohort did not receive single-shot antibiotics during surgery (52.4\%). Local anesthesia was the preferred anesthesia technique (44.8\%), followed by general anesthesia with $44.4 \%$ and sedation $(10.8 \%)$.

Table 2

TIVAD-specific data

\begin{tabular}{|lll|}
\hline & Total & Percentage \\
\hline Side of TIVAD & & \\
\hline left SV & 338 & 53.0 \\
right SV & 300 & 47.0 \\
\hline TIVAD impl. successful & & \\
\hline yes & 618 & 96.9 \\
no & 20 & 3.1 \\
\hline Antibiotics perioperative & & \\
\hline yes & 303 & 47.5 \\
no & 334 & 52.4 \\
no information & 1 & 0.2 \\
\hline Anesthesia & & \\
\hline local anesthesia & 286 & 44.8 \\
analgosedation & 69 & 10.8 \\
general anesthesia & 283 & 44.4 \\
\hline TIVAD = totally implantable venous access device, impl. = implantation, SV = subclavian vein \\
\hline
\end{tabular}

Explantation of TIVAD due to complication at our institution happened in 82 (12.9\%) patients. Median time between implantation and explantation was 143,5 days (range $0-1620$ days) and explantation was mostly performed because of an infection $(n=37)$.

Complications were observed in $115(18 \%)$ cases and most complications occurred postoperatively (11.1\% postoperative, $5.8 \%$ intraoperative, $1.1 \%$ both). The distribution of TIVAD-related complications is shown in Table 3. The most common complication was postoperative infection $(n=37)$. For patients with pneumothorax $(n=12)$, invasive management with placement of thoracic drainage was only necessary in 4 cases (33.3\% of cases with pneumothorax; $0.6 \%$ overall). Thus, the majority of pneumothoraces could be managed conservatively and overall-rate for placement of thoracic drainage after TIVAD implementation in ST was less than $1 \%$. 
Table 3

TIVAD-related complications

\begin{tabular}{|lll|}
\hline & Total & Percentage \\
\hline Complication & & \\
\hline No & 523 & 82.0 \\
Yes & 115 & 18.0 \\
intraoperative & 37 & 5.8 \\
postoperative & 71 & 11.1 \\
both & 7 & 1.1 \\
\hline Type of complication & 37 & 5.8 \\
Infection & 26 & 4.1 \\
Thrombosis & 20 & 3.1 \\
Ven. malp. & 14 & 2.2 \\
IWH & 12 & 1.9 \\
Pneumothorax & 4 & 0.6 \\
thoracic drainage & 8 & 1.3 \\
no intervention & 10 & 1.6 \\
Art. puncture & 9 & 1.4 \\
Others (requiring & & \\
revision) & & \\
Ven. malp. = venous malposition, Art. puncture = arterial puncture, IWH = impaired wound healing, \\
others (requiring revision) = all other rare complications requiring revision (defect or insufficient \\
working TIVAD, occlusion, dysfunctional TIVAD, twisted TIVAD, pain, soft-tissue emphysema) \\
\hline
\end{tabular}

Success rate of TIVAD implantation was significantly higher for insertion into the left subclavian vein than the right side. ( $98.2 \%$ vs. $95.3 \% ; p=0.036$; see Table $4 a)$. 


\section{Table 4}

a: Associations between side of TIVAD implantation and implantation success as well as occurrence, time and type of complications

\begin{tabular}{|c|c|c|c|}
\hline & $\begin{array}{l}\text { right } \\
\text { n (\%) }\end{array}$ & $\begin{array}{l}\text { left } \\
\mathrm{n}(\%)\end{array}$ & p-values \\
\hline Total $(n=638)$ & $300(47.0)$ & $338(53.0)$ & \\
\hline TIVAD impl. successful & $286(95.3)$ & $332(98.2)$ & 0.036 \\
\hline $\begin{array}{l}\text { yes } \\
\text { no }\end{array}$ & $14(4.7)$ & $6(1.8)$ & \\
\hline Complication & $57(19.0)$ & $58(17.2)$ & 0.546 \\
\hline \multicolumn{3}{|l|}{ no } & \\
\hline Time of complication & $21(36.8)$ & $16(22.6)$ & 0.559 \\
\hline intraoperative & 33 (57.9) & $38(65.5)$ & \\
\hline postoperative & $3(5.3)$ & $4(6.9)$ & \\
\hline \multicolumn{4}{|l|}{ both } \\
\hline Ven. malp.. & $13(4.3)$ & $7(2.1)$ & 0.102 \\
\hline Art. puncture & $7(2.3)$ & $3(0.9)$ & 0.203 \\
\hline Infection & $21(7.0)$ & $16(4.7)$ & 0.222 \\
\hline Pneumothorax & $3(1.0)$ & $9(2.7)$ & 0.123 \\
\hline Thrombosis & $6(2.0)$ & $20(5.9)$ & 0.013 \\
\hline IWH & $8(2.7)$ & $6(1.8)$ & 0.443 \\
\hline Others (requiring revision) & $4(1.3)$ & $5(1.5)$ & 1.0 \\
\hline
\end{tabular}

TIVAD = totally implantable venous access device, impl. = implantation, Ven. malp. $=$ venous malposition, Art. puncture = arterial puncture, IWH = impaired wound healing

Whereas there were no significant differences between left- and right-sided TIVAD implantations with regard to overall rate of complications as well as rates of most specific complications (see Table 4a), postoperative thrombosis was observed significantly more often in left-sided compared to right-sided TIVADs (5.9\% vs. $2.0 \%, p=0.013$; see Table $4 a)$. 
There was no significant association between type of performed anesthesia and rate of successful TIVAD implantations $(p=0.21)$ though success rate was the highest in case of general anesthesia (see Table 4b). However, there was a statistically significant relationship between type of anesthesia used and complication rate $(p=0.014$; see Table $4 b)$, with general anesthesia showing the lowest complication rates compared to sedation and/or local anesthesia. No statistically significant association could be found between performed anesthesiological technique and the rate of specific complications (see Table $4 \mathrm{~b}$ ); the only exception was an increased risk for venous malposition of TIVAD in local anesthesia $(p=0.047$; see Table $4 b)$. 


\section{Table 4}

\section{b: Associations between method of anesthesia and implantation success as well as occurrence, time and type of complications}

\begin{tabular}{|c|c|c|c|c|}
\hline & $\begin{array}{l}\text { General anesthesia } \\
\mathrm{n}(\%)\end{array}$ & $\begin{array}{l}\text { Local anesthesia } \\
\mathrm{n}(\%)\end{array}$ & $\begin{array}{l}\text { Analgosedation } \\
\mathrm{n}(\%)\end{array}$ & p-values \\
\hline Total $(n=638)$ & $283(44.4)$ & $286(44.8)$ & $69(10.8)$ & \\
\hline TIVAD impl. successful & $278(98.2)$ & $274(95.8)$ & $66(95.7)$ & 0.208 \\
\hline $\begin{array}{l}\text { yes } \\
\text { no }\end{array}$ & $5(1.8)$ & $12(4.2)$ & $3(4.3)$ & \\
\hline Complication & $37(13.1)$ & $64(22.4)$ & $14(20.3)$ & 0.014 \\
\hline $\begin{array}{l}\text { yes } \\
\text { no }\end{array}$ & $246(86.9)$ & $222(77.6)$ & $55(79.7)$ & \\
\hline Time of complication & $12(32.4)$ & $22(34.4)$ & $3(21.4)$ & 0.367 \\
\hline intraoperative & $24(64.9)$ & $36(56.3)$ & $11(78.6)$ & \\
\hline postoperative & $1(2.7)$ & $6(9.4)$ & $0(0.0)$ & \\
\hline both & & & & \\
\hline Ven. malp.. & $6(2.1)$ & $14(4.9)$ & $0(0.0)$ & 0.047 \\
\hline Art. puncture & $3(1.1)$ & $5(1.7)$ & $2(2.9)$ & 0.516 \\
\hline Infection & $11(3.9)$ & $20(7.0)$ & $6(8.7)$ & 0.157 \\
\hline Pneumothorax & $2(0.7)$ & $9(3.1)$ & $1(1.4)$ & 0.097 \\
\hline Thrombosis & $8(2.8)$ & $14(4.9)$ & $4(5.8)$ & 0.342 \\
\hline IWH & $2(0.7)$ & $10(3.5)$ & $2(2.9)$ & 0.069 \\
\hline Others (requiring revision) & $5(1.8)$ & $3(1.0)$ & $1(1.4)$ & 0.768 \\
\hline
\end{tabular}

Further analyses were performed to assess associations of body mass index and tumor entity with complications as well as likelihood of successful implantation. In most cases, no significant associations were found (see Table 5a for BMI and 5b for tumor entity). There were no significant differences between different BMI groups or tumor types with regard to the rate of successful implantations or the overall complication rate. However, the complication "venous malposition" was observed significantly more often in patients with $\mathrm{BMI}>30$ than in patients with lower $\mathrm{BMI}$ (underweight: $0 \% \mathrm{vs}$. normal weight: $2.3 \% \mathrm{vs}$. overweight: $1.6 \%$ vs. obesity: $6.7 \% ; p=0.027$; see Table $5 a$ ). Furthermore, both pneumothorax and 
impaired wound healing occurred significantly more frequently in patients with cervical cancer than in patients with other cancer types $(p=0.011$ and $p=0.025$, respectively; see Table $5 b)$, though absolute numbers were small.

Table 5

a: Associations between Body-Mass-Index and implantation success as well as occurrence, time and type of complications

\begin{tabular}{|c|c|c|c|c|c|}
\hline & $\begin{array}{l}\text { Underweight } \\
\text { (<BMI 18.5) } \\
\mathrm{n}(\%)\end{array}$ & $\begin{array}{l}\text { Normal weight } \\
\text { (BMI 18.5- } \\
24.9) \\
\text { n (\%) }\end{array}$ & $\begin{array}{l}\text { Overweight } \\
\text { (BMI 25- } \\
29.9 \text { ) } \\
\text { n (\%) }\end{array}$ & $\begin{array}{l}\text { Obesity } \\
\text { (BMI > 30) } \\
n(\%)\end{array}$ & p-value \\
\hline Total $(n=620)$ & $16(2.5)$ & $263(41.2)$ & $192(30.1)$ & $\begin{array}{l}149 \\
(23.4)\end{array}$ & \\
\hline $\begin{array}{l}\text { TIVAD impl.successful } \\
\text { yes } \\
\text { no }\end{array}$ & $\begin{array}{l}16(100) \\
0(0)\end{array}$ & $\begin{array}{l}256(97.3) \\
7(2.7)\end{array}$ & $\begin{array}{l}185(96.4) \\
7(3.6)\end{array}$ & $\begin{array}{l}143 \\
(96.0) \\
6(4.0)\end{array}$ & 0.749 \\
\hline $\begin{array}{l}\text { Complication } \\
\text { yes } \\
\text { no }\end{array}$ & $\begin{array}{l}3(18.8) \\
13(81.3)\end{array}$ & $\begin{array}{l}41(15.6) \\
222(84.4)\end{array}$ & $\begin{array}{l}32(16.7) \\
160(83.3)\end{array}$ & $\begin{array}{l}35(23.5) \\
114 \\
(76.5)\end{array}$ & 0.228 \\
\hline $\begin{array}{l}\text { Time of complication } \\
\text { intraoperative } \\
\text { postoperative } \\
\text { both }\end{array}$ & $\begin{array}{l}1(33.3) \\
2(66.7) \\
0(0.0)\end{array}$ & $\begin{array}{l}14(34.1) \\
24(58.5) \\
3(7.3)\end{array}$ & $\begin{array}{l}11(34.4) \\
20(62.5) \\
1(3.1)\end{array}$ & $\begin{array}{l}10(28.6) \\
22(62.9) \\
3(8.6)\end{array}$ & 0.967 \\
\hline Ven. malp. & $0(0.0)$ & $6(2.3)$ & $3(1.6)$ & $10(6.7)$ & 0.027 \\
\hline Art. puncture & $0(0.0)$ & $4(1.5)$ & $3(1.6)$ & $3(2.0)$ & 0.934 \\
\hline Infection & $1(6.3)$ & $15(5.7)$ & $8(4.2)$ & $10(6.7)$ & 0.773 \\
\hline Pneumothorax & $0(0.0)$ & $6(2.3)$ & $6(3.1)$ & $0(0.0)$ & 0.183 \\
\hline Thrombosis & $0(0.0)$ & $8(3.0)$ & $7(3.6)$ & $10(6.7)$ & 0.243 \\
\hline IWH & $1(6.3)$ & $5(1.9)$ & $4(2.1)$ & $3(2.0)$ & 0.706 \\
\hline $\begin{array}{l}\text { Others (requiring } \\
\text { revision) }\end{array}$ & $1(6.3)$ & $2(0.8)$ & $2(1.0)$ & $4(2.7)$ & 0.154 \\
\hline
\end{tabular}


Table 5

b: Associations between disease and implantation success as well as occurrence, time and type of complications

\begin{tabular}{|c|c|c|c|c|c|c|}
\hline & $\begin{array}{l}\text { Breast } \\
\text { cancer }\end{array}$ & $\begin{array}{l}\text { Ovarian } \\
\text { cancer }\end{array}$ & $\begin{array}{l}\text { Endometrial } \\
\text { cancer }\end{array}$ & $\begin{array}{l}\text { Cervical } \\
\text { cancer }\end{array}$ & $\begin{array}{l}\text { Other gyn. } \\
\text { malignoma }\end{array}$ & $\begin{array}{l}\text { p- } \\
\text { value }\end{array}$ \\
\hline Total $(n=638)$ & $\begin{array}{l}506 \\
(79.3)\end{array}$ & 88 (13.8) & $14(2.2)$ & $15(2.4)$ & $15(2.4)$ & \\
\hline $\begin{array}{l}\text { TIVAD } \\
\text { impl.successful }\end{array}$ & $\begin{array}{l}491 \\
(97.0)\end{array}$ & 85 (96.6) & 13 (92.9) & $\begin{array}{l}15 \\
(100.0)\end{array}$ & $14(93.3)$ & \multirow[t]{2}{*}{0.752} \\
\hline yes & $15(3.0)$ & $3(3.4)$ & $1(7.1)$ & $0(0.0)$ & $1(6.7)$ & \\
\hline \multicolumn{7}{|l|}{ no } \\
\hline \multirow{3}{*}{$\begin{array}{l}\text { Complication } \\
\text { yes } \\
\text { no }\end{array}$} & \multirow{2}{*}{$\begin{array}{l}85 \\
(16.8)\end{array}$} & $18(20.5)$ & $2(14.3)$ & $5(33.3)$ & $5(33.3)$ & \multirow[t]{3}{*}{0.218} \\
\hline & & \multirow[t]{2}{*}{$70(79.5)$} & \multirow[t]{2}{*}{12 (85.7) } & \multirow[t]{2}{*}{$10(66.7)$} & \multirow[t]{2}{*}{$10(66.7)$} & \\
\hline & $\begin{array}{l}421 \\
(83.2)\end{array}$ & & & & & \\
\hline \multirow{4}{*}{$\begin{array}{l}\text { Time of } \\
\text { complication } \\
\text { intraoperative } \\
\text { postoperative } \\
\text { both }\end{array}$} & \multirow{2}{*}{$\begin{array}{l}32 \\
(37.6)\end{array}$} & $3(16.7)$ & $0(0.0)$ & $1(20.0)$ & $1(20.0)$ & \multirow[t]{4}{*}{0.521} \\
\hline & & $14(77.8)$ & $2(100.0)$ & $3(60.0)$ & $4(80.0)$ & \\
\hline & $\begin{array}{l}48 \\
(56.5)\end{array}$ & $1(5.6)$ & $0(0.0)$ & $1(20.0)$ & $0(0.0)$ & \\
\hline & \multicolumn{2}{|l|}{$5(5.9)$} & & & & \\
\hline Ven. malp.. & $19(3.8)$ & $1(1.1)$ & $0(0.0)$ & $0(0.0)$ & $0(0.0)$ & 0.521 \\
\hline Art. puncture & $10(2.0)$ & $0(0.0)$ & $0(0.0)$ & $0(0.0)$ & $0(0.0)$ & 0.618 \\
\hline Infection & $25(4.9)$ & $7(8.0)$ & $1(7.1)$ & $2(13.3)$ & $2(13.3)$ & 0.332 \\
\hline Pneumothorax & $7(1.4)$ & $3(3.4)$ & $0(0)$ & $2(13.3)$ & $0(0)$ & 0.011 \\
\hline Thrombosis & $18(3.6)$ & $6(6.8)$ & $1(7.1)$ & $0(0.0)$ & $1(6.7)$ & 0.513 \\
\hline IWH & $10(2.0)$ & $1(1.1)$ & $1(7.1)$ & $2(13.3)$ & $0(0.0)$ & 0.025 \\
\hline $\begin{array}{l}\text { Others (requiring } \\
\text { revision) }\end{array}$ & $7(1.4)$ & $1(1.1)$ & $0(0.0)$ & $0(0.0)$ & $1(6.7)$ & 0.486 \\
\hline
\end{tabular}

Ven. malp. = venous malposition, Art. puncture = arterial puncture, IWH = impaired wound healing We found limited evidence for the effect of single-shot antibiotics during surgery for the prevention of port-associated infections, as there was only a trend for a decreased infection rate after single shot antibiotics ( $4 \%$ infection rate without and $7.5 \%$ infection rate with single-shot antibiotics; $p=0.058$ ). 
The two most common surgical techniques for TIVAD implantation are the venous cutdown technique (CT) and the surface landmark method using Seldinger-Technique (ST). Reviewing the literature, ST gained in importance during the last 20 years and is nowadays preferred compared to a surgical preparation of the vein as is required for the cutdown-technique $[5,6]$. Nocito et al. showed a higher success rate $(90 \%$ vs $70 \%, p=0.007)$ and a shorter time requirement $(48.9 \mathrm{~min}$. vs. $64.8 \mathrm{~min}, \mathrm{p}<0.001)$ for TIVAD implantation in ST compared to CT. There was no significant difference in TIVAD-related complication rate between both groups [7]. Hsu et al. also showed a higher success rate for TIVAD implantation using ST and no difference in overall peri- and postoperative complication rates [6]. As Blanco-Guzman described, the advantage of ST is the reduced need of surgical time and supportive equipment (e.g. ultrasound or X-ray machine), as the puncture of the vein is usually performed blind. However, intraoperative ultrasound could lead to a higher amount of correct implanted TIVADs with ST and could replace the routinely performed postoperative chest X-ray [5]. However, another study showed disadvantages for ST compared to CT with a higher rate of TIVAD associated thrombosis $(16.7 \%$ in ST vs. $10.3 \%$ in CT) and a higher rate of TIVAD dislocations ( $4.6 \%$ in ST vs. $0.3 \%$ CT) [8].

Though generally ST seems to be the more preferred method, CT could still be an adequate alternative depending on risk factors (e.g. obesity) and personal preferences of the surgeon.

In this study, postoperative infections were the most frequent complication (5.8\%). Bassi et al. reported in 2012 a similar TIVAD-infection rate (6.17\%) [9], whereas several other studies reported a higher rate of TIVAD-related infections up to $11 \%[3,10-11]$. In contrast, Bow et al. reported in a study of 1999 no TIVAD-related infection [12] and some other studies also showed less TIVAD-related infections $[5,13]$ than ours. However, comparison of complications between different studies is challenging as observation periods are not congruent and thereby interpretation of the reported data is hindered. Depending on time of appearance, etiology of the complication "infection" could be totally different. In our study the observation period was not limited, and the longest observed duration between TIVAD implantation and explantation due to occurrence of an infection was 1187 days. This infection was most probably not caused by the surgical procedure itself but more likely related to improper long-term use of TIVAD. In contrast, the shortest reported duration between TIVAD implantation and explantation because of a portassociated infection was 6 days; in this case the infection was presumably caused by the implantation procedure itself.

The rate of TIVAD-related thrombosis found in this study (4.1\%) is within the range of 1.5 up to $16.4 \%$ reported in the current literature $[2,5,11,13-18]$. Likewise, the observed incidence of the complication "venous malposition" (3.1\%) is in line with previous studies [13,16-17]. In clinical routine, especially the development of a pneumothorax following TIVAD implantation by ST is feared, but the reported low incidence found in this study is reassuring. In total, pneumothorax occurred in only $1.9 \%$ of patients $(\mathrm{n}=$ 12), and in only 4 of these patients a thoracic drainage was required. Reviewing the literature showed similar low rates (between $0.4 \%$ and $3.4 \%$ ) of pneumothoraces after TIVAD implantation in ST [2, 12-13, 16-17]. 
In a study with similar study population and design than our study, El-Balat et al. retrospectively assessed rate of complication for TIVAD implantation by gynecologists in breast cancer patients. However, the preferred method for catheter implantation was CT and ST was only used in case of a failed implantation by CT. The observed overall complication rate was $26 \%$ and thus considerably higher compared to our study $(18 \%)[14]$.

In this study, a significant higher success rate for the implantation of TIVADs in the left subclavian vein compared to the right subclavian vein was found $(98.2 \%$ vs. $95.3 \%, p=0.036)$. This finding might be explained by anatomical circumstances, as the course of the left subclavian vein is flatter than on the right side, possibly facilitating puncture of the subclavian vein and subsequent protrusion of the wire. However, discrepant results are found in the literature for side-related success rates of port implantations. Lin et al. reported a higher rate of correct position of TIVAD-tubes (transition between right atrium and Vena cava superior) for the implantation by ST on the left side compared to the right side $(p=0.001)$ [11]. In contrast, El-Balat et al. found no significant difference in success rates depending on the chosen implantation side $(p=0.43)$. However, in contrast to Lin et al. and this study, El-Balat et al. used the CT of the cephalican vein as preferred method [14]. Another study from Ma et al. reported a higher success rate for the TIVAD implantation with ST in the right subclavian vein ( $95.6 \%$ vs. $81.8 \%)$, but, in difference to the studies before, the puncture was performed supraclavicular instead of infraclavicular [19].

We could show a significant higher rate for developing a TIVAD-related thrombosis for implantation in the left subclavian vein compared to the right subclavian vein $(5.9 \%$ vs. $2.0 \%, p=0.013)$. In contrast, Biacchi et al. found an association between postoperative thromboses and implantation of TIVADs via ST into the right subclavian vein. In addition, a correlation between diameter of the catheter system and the rate of thrombosis has been described [8]. However, other studies showed no correlation between thrombosis and side of implantation $[11,14]$; thus, the findings of our study with a higher rate of thrombosis after TIVAD implantation on the left side is not supported by present literature.

The results of this study showed a significant higher rate of venous misplacements in patients with obesity. Biffi et al. defined among other factors like scares within the localization of vein puncture especially obesity as an exclusion criterion for using ST for implantation of TIVADs [2]. This recommendation is supported by our finding, which is to our knowledge the first study reporting an association between BMI and venous malposition of TIVADs for port implantation by ST.

Especially due to logistic reasons, local anesthesia is the preferred method of anesthesia for portimplantation not only at our institution as $[3,13-14,17,20]$. Interestingly, we found a significantly lower overall complication-rate with general anesthesia (13.1\%) compared to both local anesthesia and analgosedation (22.4\% and $20.3 \%$, respectively). These findings may be explained by the optimized surgical conditions in general anesthesia due to maximal relaxation of patient without any disturbance caused by incautious patient movements, pain or anxiety reactions.

Though our study showed a significant higher rate of pneumothoraces and impaired wound healing in patients with cervical cancer compared to patients with other gynecological tumor entities, no previous 
studies reporting similar findings were found. However, these results have to be interpreted carefully as the overall numbers are very small.

Even if the result was not significant, a trend favoring application of single-shot antibiotics to prevent postoperative infections was observed. However, there are several studies which could not show any benefit for perioperative antibiotics during surgery to prevent subsequent infections. A large metaanalysis including data from 2154 patients found no reduced rate of postoperative infections (within 30 days postoperative) following placement of subcutaneously implanted central venous access ports when prophylactic antibiotics were used [21]. Di Carlo et al. also showed in a randomized study comprising oncological patients that perioperative antibiotics do not provide a benefit in terms of reduced infection rates after TIVAD implantation [22]. For this study, it is important to mention that some patients received antibiotics during surgery not for port implantation but for the simultaneous surgical procedure (e.g. breast-conserving-therapy) that was combined with TIVAD implantation. In addition, infections as postoperative complications were considered independent of time of occurrence in this analysis. Thus, our findings on influence of intraoperative single-shot antibiotics on infection rates could be biased by delayed infections e.g. due to parenteral nutrition or other long-term use of the port device. Nevertheless, application of antibiotics should be considered carefully, because even if the above mentioned studies showed no benefit for perioperative antibiotics in the context of port implantations, several other studies proofed the benefit of antibiotics in surgeries using allogeneic materials (e.g. breast implants) [23-24].

A clear limitation of this study is the retrospective study design. No systemic follow up was available for the study population and data regarding date and reason of TIVAD explantation is missing for patients that had their TIVAD explanted at other clinics. In addition, information on complications which occurred after the last contact with our institution could have been missed. As another weakness it needs to be mentioned that complications were not further classified regarding degree of severity, e.g. by using the Clavien-Dindo classification. Although the total number of included patients is higher than in most other published studies on this topic, sample sizes for some complications or patients sub-cohorts were still rather small, and rare complications could not be observed in some of the smaller patient cohorts. Furthermore, because the significance level was not adjusted for multiple testing, results of the statistical analyses have to be interpreted carefully. Overall, more large studies with extended observational periods are essential to facilitate detection of both rare complication events and long-term complications such as TIVAD malfunction, thrombosis or infections that may occur several months after TIVAD implantation.

One of the major strengths of the study besides the large number of patients is that it comprises a clearly defined patient cohort including only female patients with gynecological malignancies. Thus, our results are not affected by a potential gender bias, as differences in anatomy between men and women may influence the success rate of TIVAD implantation via ST or the risk for specific complications. As a singlecenter analysis, this study also benefits from consistent standards in surgical technique, postoperative procedures and subsequent surveillance 
Overall, the presented results provide a good basis for optimized counseling of female patients with planned TIVAD implantation regarding surgical procedures, success rate, and probability of suffering from complications.

\section{Conclusion}

Seldinger-Technique is an effective and safe procedure for TIVAD implantation in female patients with gynecologic malignancies. The rate of complications observed in this study is low and complications mostly consist of infections followed by thrombosis. Perioperative application of antibiotics should be considered in all cases. Local anesthesia is an adequate method of anesthesia for this surgical intervention in most cases. However, especially for patients with a high potential for complications such as obesity with $\mathrm{BMI}>30 \mathrm{~kg} / \mathrm{m}^{2}$, general anesthesia should be preferred; alternatively, the use of venous cut-down technique could be considered. In the absence of specific clinical factors favoring implantation in the right side, TIVAD implantation into the left subclavian vein is recommended as this is associated with a significantly higher success rate.

\section{Declarations}

\section{Ethical approval and consent to participate}

Ethical approval was given by the local Ethics Committee (Ethics Committee University Ulm, approval no $320 / 18)$. No separate informend consent of patients was obtained as theses analyses were performed retrospectively with anonymized data and therefore according to the local EC Ulm no informed consent was necessary.

\section{Consent for publication}

Not applicable.

\section{Availability of data and materials}

The datasets generated during and analysed during the current study are not publicly available due to privacy policy and in respect for the individual patients' personal privacy, because of their disease and treatment this retrospective data collection was possible, but are available from the corresponding author on reasonable request.

\section{Competing interests}

The authors declare that they have no competing interests 


\section{Funding}

No funding.

\section{Authors' contributions}

K.E.: Conceptualization, writing original draft

C.B.: Conceptualization, review \& editing

F.S.: Review \& editing

N.dG.: Review \& editing

F.E.: Review \& editing

D.D.: Review \& editing

T.F.: Data curation, Formal analysis, review

W.J.: Supervision and review

A.dG.: Conceptualization, resources, review \& editing

\section{Acknowledgements}

Not applicable.

\section{References}

1. Niederhuber J E, Ensminger W, Gyves J W, et al.: Totally implanted venous and arterial access system to replace external catheters in cancer treatment. Surgery, 1982, 92. Jg., Nr. 4, S. 706-712

2. Biffi R, De Braud F, Orsi F, et al.: Totally implantable central venous access ports for long-term chemotherapy. A prospective study analyzing complications and costs of 333 devices with a minimum follow-up of 180 days. Annals of Oncology, 1998, 9. Jg., Nr. 7, S. 767-773

3. Ji L, Yang J, Miao J, et al.: Infections Related to Totally Implantable Venous-Access Ports: Long-Term Experience in One Center. Cell Biochemistry and Biophysics, 2015, 72. Jg., Nr. 1, S. 235-240

4. Kurul S, Saip P, Aydin T: Totally implantable venous-access ports: Local problems and extravasation injury. The lancet oncology, 2002, 3. Jg., Nr. 11, S. 684-692.

5. Blanco-Guzman M 0: Implanted vascular access device options: a focused review on safety and outcomes. Transfusion, 2018, 58. Jg., S. 558-568. 
6. Hsu C C T, Kwan G N C, Evans-Barns H, Rophael J A, van Driel M L: Venous cutdown versus the Seldinger technique for placement of totally implantable venous access ports. Cochrane Database of Systematic Reviews, 2016, Nr. 8.

7. Nocito A, Wildi S, Rufibach K, Clavien P A, Weber M: Randomized clinical trial comparing venous cutdown with the Seldinger technique for placement of implantable venous access ports. British Journal of Surgery, 2009, 96. Jg., Nr. 10, S. 1129-1134.

8. Biacchi D, Sammartino P, Sibio S, et al.: Does the Implantation Technique for Totally Implantable Venous Access Ports (TIVAPs) Influence Long-Term Outcome? World journal of surgery, 2016, 40. Jg., Nr. 2, S. 284-290.

9. Bassi K K, Giri A K, Pattanayak M, Abraham S W, Pandey K K: Totally implantable venous access ports: Retrospective review of long-term complications in 81 patients. Indian Journal of Cancer, 2012, 49. Jg., Nr. 1, S. 114.

10. Beckers M M J, Ruven H J T, Seldenrijk C A, Prins M H, Biesma D H: Risk of thrombosis and infections of central venous catheters and totally implanted access ports in patients treated for cancer. Thrombosis research, 2010, 125. Jg., Nr. 4, S. 318-321.

11. Lin W Y, Lin C P, Hsu C H, et al.: Right or left? Side selection for a totally implantable vascular access device: A randomised observational study. British journal of cancer, 2017, 117. Jg., Nr. 7, S. 932-937.

12. Bow E J, Kilpatrick M G, Clinch J J: Totally implantable venous access ports systems for patients receiving chemotherapy for solid tissue malignancies: A randomized controlled clinical trial examining the safety, efficacy, costs, and impact on quality of life. Journal of Clinical Oncology, 1999, 17. Jg., Nr. 4, S. 1267-1267.

13. Gurkan S, Seber S, Gur O, et al.: Retrospective evaluation of totally implantable venous access port devices: Early and late complications. J buon, 2015, 20. Jg., Nr. 1, S. 338-345.

14. El-Balat A, Schmeil I, Karn T, et al.: Catheter-related complications of subcutaneous implantable venous access devices in breast cancer patients. in vivo, 2018, 32. Jg., Nr. 5, S. 1275-1281.

15. Fischer L, Knebel P, Schröder S, et al.: Reasons for explantation of totally implantable access ports: $A$ multivariate analysis of 385 consecutive patients. Annals of surgical oncology, 2008, 15. Jg., Nr. 4, S. 1124-1129.

16. Güner O S, Tümay L V, Zorluoğlu A, Orhan B: Subclavian venous port catheter implantation in general surgery: 238 cases from a single center. Türkiye Klinikleri Tıp Bilimleri Dergisi, 2013, 33. Jg., Nr. 5, S. $1330-1336$.

17. Kim J T, Oh T Y, Chang W H, Jeong Y K: Clinical review and analysis of complications of totally implantable venous access devices for chemotherapy. Medical oncology, 2012, 29. Jg., Nr. 2, S. $1361-1364$.

18. Ozyuvaci E, Kutlu F: Totally implantable venous access devices via subclavian vein: A retrospective study of 368 oncology patients. Advances in therapy, 2006, 23. Jg., Nr. 4, S. 574-581.

19. Ma L, Liu Y, Wang J, et al.: Totally implantable venous access port systems and associated complications: A single-institution retrospective analysis of 2,996 breast cancer patients. Molecular 
and clinical oncology, 2016, 4. Jg., Nr. 3, S. 456-460.

20. Aziret $M$, Irkörücü $O$, Gökler $C$, et al.: Performance of venous port catheter insertion by a general surgeon: A prospective study. International Surgery, 2015, 100. Jg., Nr. 5, S. 827-835.

21. Nelson E T, Gross M E, Mone M C, et al.: A survey of American College of Surgery fellows evaluating their use of antibiotic prophylaxis in the placement of subcutaneously implanted central venous access ports. The American Journal of Surgery, 2013, 206. Jg., Nr. 6, S. 1034-1040.

22. Di Carlo I, Toro A, Pulvirenti E, et al.: Could antibiotic prophylaxis be not necessary to implant totally implantable venous access devices? Randomized prospective study. Surgical oncology, 2011, 20. Jg., Nr. 1, S. 20-25.

23. Babu S, Al-Obaidi B, Jardine A, et al.: A comparative study of 5 different antibiotic prophylaxis regimes in 4500 total knee replacements. Journal of Clinical Orthopaedics and Trauma, 2020, 11. Jg., Nr. 1, S. 108-112.

24. Bertaglia E, Zerbo F, Zardo S, et al.: Antibiotic prophylaxis with a single dose of cefazolin during pacemaker implantation: Incidence of long-term infective complications. Pacing and clinical electrophysiology, 2006, 29. Jg., Nr. 1, S. 29-33 